\title{
PEMAHAMAN TERHADAP METAFOR SEBAGAI SUMBER KEARIFAN MASYARAKAT
}

\author{
Understanding Metaphors as Source of Community Wisdom
}

\author{
Margaretha Liwoso
}

\begin{abstract}
Abstrak
Pengggunaan metafor di dalam teks bahasa asing dapat diasumsikan menimbulkan kesenjangan pemahaman makna bahasa sumber. Teks bahasa asing terdiri dari makna implisit yang terbentuk melalui latar belakang pengetahuan masyarakat. Dalam hal ini, makna bahasa dan budaya yang berbeda tidak selamanya mudah dianalogikan secara langsung dari bahasa sumber ke bahasa sasaran, tanpa mempertimbangkan makna implisit yang terkandung di dalam bahasa sumber. Sejauh ini, para ahli sedang berupaya mencoba menemukan cara untuk menyelesaikan masalah kesalahpahaman karena implikasi metaforis.Dalam hal ini, kemungkinan kesenjangan pemahamanmempengaruhi penerjemahan dari bahasa sumber ke bahasa target. Bagaimanapun, dengan mengeksplorasi aspek-aspek metafor bahasa, akan dapat diekspresikan kearifan masyarakat sebagai bagian kehidupan mereka.
\end{abstract}

Kata Kunci: metafora, kesalah-pahaman, makna, bahasa asing, bahasa sumber

\begin{abstract}
The use of metaphor in foreign language texts should assumed to be a gap of meaning and thus misunderstanding to the source language. It contains implicit meaning which is formed by the background of community knowledge. In this case, the meaning of the different language and culture is not always easy to be analogized directly from the source language to the target language, without considering the implicit meaning which is involved in the source language. So far, the experts are in progress of trying and finding out the way to solve the problem of misunderstanding because of metaphorical implications in the source language. In this case, the possible gap of understanding is influenced by the translation from the source language to the target language. However, by exploring the metaphorical aspects of the language, will likewise be expressed the community wisdom as part of their life.
\end{abstract}

Keywords: metaphor, misunderstanding, meaning, foreign language, source language

\section{Pendahuluan}

14 | Ranah, Volume 1, Nomor 2, Desember 2012 
Perkembangan dunia secara global tidak terlepas kaitannya dengan kegiatan manusia di berbagai bidang dan lebih khusus lagi demi kelanjutan hidup manusia. Hal ini berlangsung seiring dengan perkembangan bahasa dan budaya sebagai bagian yang tidak terpisahkan dari kehidupan manusia.

Sampai dengan akhir tahun 70-an and 80-an, muncul pendapat para linguis dan sarjana yang menganggap metaphor sebagai bagian ucapan yang tidak wajar, tulisan indah yang puitis yang lebih mengarah ke bahasa yang dekoratif (Stern, 2006). Bahkan, ada juga pendapat bahwa "Metaphors were seen as 'deviant'and needed to be explained in terms of 'normal' language usage (Ortony, 1993)". Dengan kata lain, metafor merupakan penyimpangan yang perlu dijelaskan melalui bahasa yang lumrah digunakan.

Hal yang perlu diperhitungkan juga pendapat Burke (1945), yang justru membangun suatu idea yang kemudian diambil alih oleh para linguis, bahwapendekatan metafor dapat membangun suatu karakter melalui berbagai perspektif. Dengan demikian, pemahaman terhadap sesuatu akan berhadapan dengan sejumlah perspektif atau akan berhadapan dengan multi-ekspresi.

Pada akhir tahun 70-an George Lakoff, Mark Johnson, dan Michael Reddy, lebih mempertegas bahwa metafor bukan hanya benar-benar wajar, tetapi juga berkaitan dengan pemikiran dan tindakan (Stern, 2006). Bahkan Saffer (2005), menyadari bahwa metafor berperan juga di dalam interaksi desain, sebagaimana kutipan berikut: [...] metaphor can be a powerful tool for designers, in both the process of designing and within the products themselves. Metaphor can help redefine design problems and help solve them. It canbe used as a research tool, to understand new subject areas, or as means togenerate new ideas about familiar subjects.

Namun, di dalam artikel singkat ini hanya akan diungkapkan sejumlah contoh yang mengarah ke peran metaphor sebagai sumber kearifan masyarakat.

\section{Pengertian Metafor dan Penggunaan}

Kata metafor dijabarkan dari kata Greek metaphoria, yang berarti membawa. Metafor ialah suatu fenomena dengan perbandingan yang berbeda antara beberapa maksud. Hal ini adalah kondensasi beberapa bagian, seperti topik atau penanda dengan makna konotatif.

Definisi awal metafor menurut ekspresi Aristoteles sebagaimana sebuah kapal yang membawa sebuah kata dari penggunaan yang normal ke sesuatu yang baru. (Richards, 1965:89). Sebagai contoh kalimat: The customary is king (pembeli adalah raja). Metafor ini berkembang dari kata raja ke sejumlah peran yang dimiliki seorang raja, antara lain: berpengaruh, orang yang penting, memiliki kekuasaan, dan kualitas ini dilekatkan kepada seorang pelanggan.

Contoh yang lain, terkandung di dalam metaphora ship of state, kata ship dapat dikembangkan melalui unsur-unsur yang terkait, antara lain: kapten kapal mengandung konotasi pemerintahan, lautan berkonotasi alur waktu, cuaca buruk mengindikasikan suatu krisis dan tanpa angin mengindikasikan adanya stagnasi ekonomi.

Metafor atau yang juga diistilahkan dengan majas termasuk ungkapan yang telah lama digunakan, yang mulanya hanya meliputi pengertian figure of speech sebagaimana Djajasudarma (2009:84). Selanjutnya, Alhasnawi (lihat Fadee, 2011:19), menyebutkan,

"Figures of speech are imaginative tools in both literature and ordinary communications 
used for explaining speech beyond its usual usage. Demikian juga, The Collins English Dictionary (2006), defined figure of speech as an expression such as a simile, in which words do nothave their literal meaning, but are categorized asmulti-word expressions that act in the text as units".

Dengan demikian, gaya bahasa sebagai alat imaginatif yang digunakan di dalam kesastraan dan di dalamkomunikasi yang lazim, untuk menjelaskan tuturan di balik penggunaannya sebagaimana biasanya. Selain itu, gaya bahasa, dianggap sebagai ekspresi simili, kata-kata tidak lagi memiliki makna literal, tetapi dikategorikan sebagai kata dengan multi-ekspresi yang berlangsung di dalam bagian-bagian teks.

Namun, multi-ekspresi yang terkandung di dalam teks hanya dapat dipahami karena ada literal meaning sebagai bahan perbandingan. Dengan kata lain, posisi interpretasi metaforis bukan hanya didasarkan pada konteks nonliteral melainkan perlu juga dilihat perbandingannya dengan konteks literal secara umum.

Menurut Stern (2006:243), metafor berada di wilayah kajian pragmatik dan bukan semantik. Dalam hal ini, Stern membedakan makna kalimat, dan apa yang dimaksudkan dengan kalimat itu sendiri, dari segi penutur dan tuturan, dan apa yang dimaksudkan oleh penutur, adalah sesuatu yang alami (natural). Selanjutnya, dikatakan ada tiga alasan mengapa metaphor cenderung dikategorikan ke penggunaan (pragmatik) daripada makna linguistik: (1) Interpretasi metaforis berkaitan dengan penggunaan ekspresi, atau interpretasi yang bervariasi dari satu tuturan ke tuturan yang lain. Oleh karena itu, Stern membedakan nosi semantik (maksudnya secara semantik) dan makna harafiah. Demikian juga, dapat dikatakan setiap individu memilikitipe ekspresi masing-masing. (2) Interpretasi tergantung pada tujuan pembicara atau apa yang dimaksudkan penutur untuk diperhatikan oleh pendengar. (3) Kondisi yang benar atau kandungan proporsional (sepadan) tergambar pada asosiasi-asosiasi ekstra linguistik dengan perkiraan yang beragam.

Pada dasarnya yang menjadi dasar makna metaforis tidak terlepas kaitannya dengan penggunaan bahasa secara pragmatis sebagaimana teori umum simbol. Didalam ensiklopedia Britanica. Simbol didefinisikan sebagai elemen komunikasi yang merepresentasikan kompleks seseorang, objek, kelompok, atau ide. Hal itu berkaitan dengan gaya bahasa yang digunakan untuk meningkatkan keindahan teks dan mengandung makna kiasan di samping makna literal (Fadaee, 2011:19). Selanjutnya, dikatakan simbol kesastraan adalah sesuatu yang berarti lebih daripada apa adanya. Hal itu adalah suatu objek, seseorang, suatu situasi, suatu tampilan, atau beberapa item yang lain yang mengandung makna literal di dalam cerita, tetapi menyarankan atau menampilkan makna lain juga.

Pada dasarnya metafor memiliki fitur khusus yang membuatnya berbeda dengan bahasa literal. Berikut ini contoh metaphor (figurative language) dan ordinary sentence (nonfigurative language) dalam bahasa Inggris:

1. Figurative Language (FL) : John is a lion (metaphor).

2. Nonfigurative Language (NFL) : That animal is a lion (ordinary sentence).

3. $F L$

: The book is as heavy as an elephant (simile).

4. NFL

: The box is as heavy as my suitcase (ordinary sentence).

Selain itu, kata lion dapat diartikan sebagai simbol keberanian atau keteguhan. Demikian juga, kata elephant dapat diartikan sebagai simbol kebesaran. 
Fitur lain metafor adalah perumpamaan atau perbandingan (imagery).

Contoh dalam bahasa Inggris:

1. Figurative Language : The sea froth is like a pearl on the shore's neck (simile).

2. Nonfigurative Language: The sea froth comes towards the shore (ordinary sentence).

Contoh dalam bahasa Jerman, FL: Wer A sagt, muss auch $B$ sagen (siapa yang mengatakan A harus juga mengatakan B). NFL: Wer A sagt muss sollte konsekuen sein, eine sache weiter zu führen (siapa yang mengatakan A harus konsekuen, menyelesaikan hal itu).

Menurut Perrine (1974:214), lingkup pemahaman makna simbolik berbeda dengan metaphor dengan memperhatikan beberapa hal berikut.

(1) Cerita itu sendiri harus lengkap dengan petunjuk secara detail yang dapat mengungkapkan ciri-ciri simbol. Dalam hal ini, fenomena simbolik dapat diidentifikasi melalui repetisi, penekanan, atau posisi.

(2) Makna suatu simbol harus dibangun dan didukung oleh seluruh konteks cerita. Hal ini berarti makna simbolik dapat diidentifikasi di dalam teks dan bukan di luar teks.

(3) Sesuatu yang disebut simbol adalah suatu item yang menyarankan makna yang berbeda dengan makna literal.

(4) Sebuah simbol dapat mengandung lebih daripada satu makna. Namun, simbol berbeda dengan metafor terutama karena simbol tidak mengandung perbandingan, tetapi melalui asosiasi yang menampilkan sesuatu lebih daripada simbol itu sendiri. Contoh: Salib sebagai simbol kekristenan, makna simbolik tidak muncul melalui perbandingan, tetapi secara langsung melalui tanda salib itu sendiri.

Selain makna metafor yang bernuansa positif, ada juga yang disebut bentuk metafor yang dapat menimbulkan kesalahpahaman pengertian karena ketidakpahaman terhadap konsep yang terkandung secara implisit di dalam pernyataan metaforis. Contoh dalam bahasa Jerman, Sie sind schon hundemüde. Arti dalam bahasa Indonesia "Anda sudah lelah seperti anjing". Bagi orang Jerman kalimat ini sangat menyenangkan karena dengan arti yang positif dan dimengerti dengan baik. Tetapi, bagi pemakai bahasa lain, khususnya orang Indonesia konotasinya sangat negatif, bahwa seseorang dibandingkan dengan anjing yang lelah. Kalau mengerti makna metaforis kalimat tersebut, seseorang juga akan merasa senang jika seseorang menyebutkan kalimat tersebut terhadap orang lain, yang artinya: "Anda sangat lelah". Namun, di dalam konteks ini aspek nonverbal juga ikut berperan, yakni melalui aspek kinesik (body language). Seseorang yang menyebutkan kalimat tersebut harus dengan ekspresi wajah yang menyenangkan orang yang menjadi lawan tutur.

Frase hündemüde terdiri atas dua kata hünde (anjing) dan müde (lelah). Bila digunakan secara terpisah akan merujuk ke arti sebenarnya. Jadi, gabungan kedua kata tersebut hanya dalam kaitan dengan makna metaforis.

Berikut ini akan dijelaskan metafor yang menggunakan kata anjing (hund), dinding (wand), jalan (weg), waktu (zeit) sebagai kata-kata yang mengalami perubahan menjadi objek atau konsep lain berdasarkan kias atau pertautan dengan objek tertentu, sebagaimana penjelasan berikut ini:

(1) Pengertian kata hund (anjing) sebagai kias, antara lain:(a) dem Menschenverbundenes, wachsames haustier (berkaitan dengan manusia, binatang peliharaan penjaga 
rumah). (b) Schimpfwort für: einen gerissenen, gemeinen, hinterhältigen oder brutalen Mitmenschen (kata makian untuk suatu kelicikan, kenakalan, ketertutupan atau kebrutalan terhadap manusia)

(2) Penggunaan kata wand (dinding) sebagai kias, wand, die, (Deutsch), etwas an die Wand fahren (sesuatu yang bertabrakan dengan dinding). Contoh: Leute, wenn wir so weitermachen, fahren wir den Laden hier an die Wand (Saudara, kalau kita melanjutkan usaha ini, kita akan bertabrakan dengan dinding). Maksudnya, suatu peringatan kepada seseorang, kalau meneruskan usaha tersebut akan mengalami kebangkrutan atau kegagalan.

(3) Penggunaan kata weg (jalan) di dalam konteks dengan makna positif:

weg, der (Deutsch); einzig bekannte Wendung (satu-satunya ekspresi yang lazim): "Wir sind auf einem (sehr) guten Weg." (Kita berada di dalam situasi yang baik). "Auf sehr gutem Weg" (di jalan yang baik), artinya "Es läuft tatsächlich gut" (sesuatu yang berlangsung dengan baik).

Arti kata weg yakni "jalan", tetapi secara metaforis tidak digunakan sebagaimana artinya. Sebenarnya, kata "jalan" dalam bahasa Indonesia digunakan juga dengan makna metaforis. Misalnya: (a) Kami kehilangan jalan (cara) untuk memecahkan masalah itu; (b) Kami kehilangan jalan (tersesat).

(4) Penggunaan kata Zeit (waktu): zeit/fenster, das, (Deutsch); für ein Ereignis verfügbares zeitkontingent (untuk suatu perencanaan hanya tersedia sekian banyak waktu). Contoh: "Für das projekt haben wir ein zeitfenster von 48 stunden". Untuk proyek ini, kita hanya memiliki 48 jam. Kata zeitfenster terdiri atas dua kata: zeit (waktu), dan fenster (jendela), secara harfiah artinya jendela waktu. Kalau frase ini dipertahankan dengan makna secara harfiah (literal), tidak akan menjawab makna metaforis, yakni durasi (jangka waktu). Maksudnya, jangka waktu yang diberikan hanya 48 jam ( 2 hari), seandainya tidak diselesaikan dalam waktu yang ditentukan, proyek atau kegiatan yang diharapkan atau ditargetkan akan gagal.

Di Jerman, sebagaimana di Indonesia, dikenal adanya pemakaian bahasa sebagai pribahasa (sprichwort) dan juga yang dikenal di dalam bahasa Jerman dengan redensarten. Pribahasa dan ucapan rakyat (redensart) dalam bahasa Jerman dikenal dengan beberapa fungsi, antara lain:

\section{(a) Sebagai Cermin Kehidupan (Lebensspiegel)}

Pribahasa dan ucapan rakyat (redensart) yang dimaksud terkait dengan berbagai aspek kehidupan yang menggunakan bahasa yang dapat ditemukan di dalam komunikasi: jual-beli, pertanian, kerja tangan, pelayaran dan kehidupannya sepanjang waktu, termasuk pengetahuan menyangkut berbagai kegiatan kehidupan tersebut (Röhrich und Mieder, 1977: 65). Misalnya, Jemanden ins handwerk pfuschen (seorang awam yang mengganggu pekerjaan orang yang ahli). Jemanden= seseorang; handwerk= ahli; pfuschen= mengacaukan. Contoh lain, Der stümper macht die meisten späne (seseorang yang tidak mahir dalam suatu pekerjaan paling banyak serbuk kikirannya/ sampah). Kata der Stümper= bodoh (tidak mahir); macht (machen)= membuat; meisten=kebanyakan; späne= sampah (kikiran). Peribahasa ini selaras dengan pribahasa dalam bahasa Indonesia, Tong kosong berbunyi nyaring. Maksudnya, orang yang selalu bersuara paling keras padahal tidak memiliki pengetahuan yang cukup. 
Blauen Montag machen (membuat Senin biru). Maksudnya, andaian pada orang yang malas, tidak masuk kerja dan tidak mau bekerja. Dalam bahasa Indonesia dikenal juga Rabu kelabu (hari yang tidak menyenangkan). Lehrgeld zahlen (membayar uang belajar). Maksudnya, bukan dalam bentuk uang kontan, melainkan andaian pada seseorang yang mengalami kemalangan, namun ada hikmahnya sehingga peristiwa ini menjadi pelajaran yang berguna.

Klappern gehoert zum handwerk (bunyi adalah bagian pekerjaan). Maksudnya, setiap pekerjaan yang menarik perhatian adalah bagian orang yang bekerja. Termasuk seseorang yang menyuarakan hasil pekerjaannya (dapat juga dengan makna positif). Namun, dapat juga sebaliknya, dianggap sebagai seorang yang memuji diri sendiri. Dalam bahasa Jerman, Eigen lob stinkt artinya "mereka yang memuji diri sendiri berbau."

\section{(b) Kepercayaan dan Ucapan Rakyat}

Bahasa yang berkaitan dengan kepercayaan dan ucapan rakyat (redensarten) termasuk gaya bahasa yang digunakan di setiap bidang kehidupan manusia. Dapat secara individu dan dapat juga secara kelompok atau di dalam masyarakat yang lebih luas. Ucapan rakyat dapat dipengaruhi oleh kebiasaan dan perilaku masyarakat.

Jeder ist seines glückes schmied (setiap orang bertanggung jawab sendiri untuk nasib yang baik). Nägel mit köpfen machen; in einer sache gut beschlagen sein (paku yang dibuat berkepala). Maksudnya, di dalam suatu hal akan lebih mudah dikerjakan atau agar sesuatu yang dibuat dapat berhasil dikerjakan. Hal ini ditujukan kepada seseorang yang harus membuat perencanaan agar tujuan dapat tercapai.

Ränke schmieden vor die rechte Schmiede kommen. Schuster bleib bei deinem leisten, alles über einen leisten schlagen: wissen, wo einen der schuh drückt. Maksudnya, peganglah apa yang kita ketahui seperti seorang tukang sepatu. Tidak melampaui ukuran yang dibuatnya, semuanya diukur sesuai dengan ukuran yang sesuai dengan pengetahuannya sehingga sepatu yang dibuat tidak menyiksa orang yang memakainya. Maksudnya, seseorang sebaiknya tidak melampaui apa yang diketahuinya atau yang dikuasainya, tidak melakukan apa yang melampaui kemampuannya agar hasil perbuatannya tidak membawa akibat buruk atau menyusahkan orang lain. Erst denken, dann handeln (dipikirkan dulu kemudian ditangani atau dikerjakan). Maksudnya, lakukan semua pekerjaan dengan dipikirkan dulu secara matang. Geiz ist die wurzel allen Übels (kepelitan adalah akar semua kejahatan). Maksudnya, seseorang yang selalu berpikir negatif adalah mereka yang menjadi sumber kejahatan.

Leben und leben lassen (hidup dan biarkan hidup). Maksudnya, biarkan mahluk hidup untuk menikmati hidup mereka. Lass die Leute leben (biarkan orang lain hidup).

\section{(c) Sebagai Cermin Karakter Nasional}

Goethe seorang pengarang klasik Jerman membuat spruch (peribahasa) tentang karakter suatu bangsa. Sprichwort bezeichnet Nationen; muss aber erst unter ihnen wohnen. (Peribahasa memberikan identitas kebangsaan, tetapi harus hidup bersamanya supaya menjadi akrab dengannya). Maksudnya, seseorang harus benarbenar menyatu dengan tempat dia hidup, barulah benar-benar mendapat identitas yang mewakili bangsanya. Ehrlich währt am längsten (kejujuranlah yang bertahan paling lama). Maksudnya, andaian kepada orang yang mempertahankan kejujuran 
Pemahaman Terhadap Metafor....

adalah orang yang paling berharga. Ohne fleiss kein preis (tanpa kerajinan tidak akan ada penghargaan). Maksudnya, seseorang akan berhasil hanya dengan kerja keras. Sejumlah contoh, sprichwort (peribahasa) dan redensarten (ucapan rakyat), kepercayaan tersebut termasuk prinsip kearifan yang menjadi panutan masyarakat. Tentu saja peribahasa (sprichtword) atau ucapan rakyat (redenarts) sebagai bentuk yang bermakna metaforis, terutama karena makna yang ditemukan bukanlah bermakna denotatif, melainkan dengan makna konotatif dan bahkan bermakna multi-ekspresi. Demikian juga, tanpa mengesampingkan, bahwa di setiap negara memiliki peribahasa, ucapan rakyat, ataupun pedoman yang berkaitan dengan kehidupan masyarakat, bangsa, dan negaranya.

Berdasarkan sejumlah kalimat yang diajukan sebagai contoh, dapat dikatakan bahwa penerjemah yang tidak menguasai aspek metafor bahasa sumber (source language) akan berhadapan dengan kesalahpahaman di dalam penerjemahan. Banyak ahli yang mengakui hal ini (Newmark, 1988; Larson, 1984). Para ahli mengakui apabila bentuk metafor diterjemahkan secara harfiah atau secara kata demi kata akan mengakibatkan

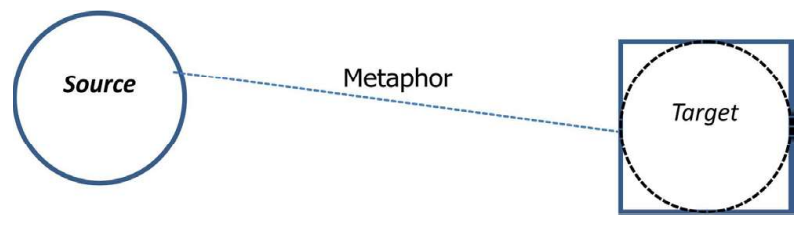

kesalahpahaman pengertian.

\section{A model of cross-domain mapping, after Wulff, Evenson and Rheinfrank, 1990.}

Menurut Ericson (Stern, 2005:6), ide tentang cross-mapping termasuk pandangan inti metafor. Selanjutnya, melalui model ini dapat dimengerti hal baru tentang apa yang dapat digunakan untuk memahami sesuatu yang sudah diketahui sebelumnya. Demikian pula, metafor dapat menjadi model alami dari sesuatu atau konsep yang tidak diketahui atau abstrak dapat disusun kembali, memungkinkan pengakraban dengan objek secara jelas. Dengan pengalaman ini, dengan memberikan struktur dan makna.

Berdasarkan sejumlah pernyataan metaforis yang dikemukan, ada beberapa hal yang dapat diidentifikasi sebagai penyebab kesalahpahaman pengertian, antara lain sebagai berikut.

(1) Makna ekstra-lingual yang digunakan di dalam pernyataan metaforis tidak dikenal di dalam bahasa sasaran (target language).

(2) Padanan yang sulit ditemukakan karena adanya makna implisit.

(3) Kemiripan ataupun kesamaan dapat diartikan berbeda berdasarkan latar budaya masing-masing.

(4) Bahasa sasaran (target language) tidak memiliki bahan banding sebagaimana bahasa sumber (source language).

(5) Setiap bahasa diciptakan secara berbeda sesuai dengan cara tertentu yang sulit dianalogikan, khususnya menyangkut aspek metafor.

Adanya kesulitan penerjemahan dengan teks yang di dalamnya mengandung metafor, memerlukan solusi untuk mengatasi persoalan ini, antara lain sebagai berikut.

(1) Metafor dapat dipertahankan jika ada kewajaran dan kejelasan. 
(2) Menyebutkan perbandingannya secara eksplisit.

(3) Mencari pengganti metafor yang maknanya sama.

(4) Memberikan keterangan kesamaannya.

(5) Makna metafor dijelaskan tanpa menggunakan bentuk metafornya.

\section{Simpulan}

Permasalahan yang perlu dihadapi dalam kaitan dengan metafor, terutama adanya kesenjangan yang terjadi karena ketidakpahaman terhadap bahasa sumber yang tersamar atau implisit. Bahkan, keragaman pengetahuan masyarakat menyebabkan tidak memungkinkan bahasa atau budaya yang satu dianalogikan dengan yang lain secara langsung.

Sejauh ini para ahli pun sedang berusaha merumuskan cara yang dapat digunakan untuk menjembatani kesalahpahaman yang mungkin muncul karena perbedaan tersebut.

Di samping itu, masalah penerjemahan dari bahasa sumber ke bahasa sasaran yang bernuansa metaforis menimbulkan persoalan di sisi yang lain, bahkan ada ahli mencari solusi dengan mengabaikan aspek metafor.

Namun, hal yang menarik di dalam mengkaji metafor, bahwa semakin menelusuri keragaman metafor yang berasal dari konteks budaya dan bahasa yang berbeda akan ditemukan beragam bentuk kearifan masyarakat yang dapat dijadikan sebagai dasar pemikiran di dalam menghadapi era globalisasi. 


\section{Daftar Pustaka}

Brüder Grimm. 1919. Deutsches Wörterbuch, Art. "Sprichwort" in Bd. X, Sp. 62-70. Djajasudarma, Fatimah. 2009. Semantik. Refika Aditama: Bandung

Dellinger, Brett, 1995. http://users.utu.fi/bredelli/cda.html

Dreyfus, L. Hebert \& Paul Rabinov. 1982. Michael Foucault: Beyond Structuralism and Hermeneutics. The Harvester Press Limited, University of Chicago: New York, London.

Dijk, A Teun van (ed.). 1985. Discourse and Communication: New Approaches to the Analysis of Mass Media. Walter de Gruyter: Berlin, New York.

-------. 2003. Ideology: A Multidisciplinary Introduction. Internet course for the Oberta de Catalunya (UOC). Copyright Spanish version with Ariel, Barcelona.

Ertelt-Vieth A. How to Analyze and Handle Cultural Gaps in German Everyday Life (from the Perspective of Exchange Students). Режим доступа: http: www. interculture-online.de \info_dlz/ertelt_vieth_04_03.pdf

Fadee, Alaheh. 2011. "Symbols, Metaphors and Similes in Literature: A casestudy of "Animal Farm" dalam Journal of English and Literature Vol. 2(2), pp. 1927, February 2011, ISSN 2141-2626 @2011 Academic Journals.

Grodzki E. 2003. Using Lacuna Theory to Detect Cultural Differences in American and German Automotive Advertising. Frankfurt (Main): Peter Lang.

Rochrich, Lutz, et al. 1977. Sprichtwort. Sammlung Metzler Band 154, J.B. Metzlersche Verlagsbuchhandlung: Stuttgart: Deutschland.

Saffer, Daniel.2005. The Role of Metaphor in Interaction Design. The School of Design Carnegie Mellon University (C2005 Daniel Saffer, Pittsburgh, Pennsylvania.

Stern, Joseph. 2006. Mind \& Language, Journal compilation (CBlackwell Publishing Ltd Vol. 21 No. 3 June 2006, pp. 243-279.

Webster's New World College Dictionary Copyright (C2009 by Wiley Publishing, Inc., Cleveland, Ohio. Used by arrangement with John Wiley \& Sons, Inc. 